\title{
Magnetic Resonance Imaging (MRI) in Diagnosis of Hip Joint Disability in Adults
}

\author{
MOHAMMED A. HAMMAD, M.Sc.; HANAN A. NAGY, M.D.; DINA MOGHAZY MOHAMED, M.D. and \\ MOHAMMED F. DAWOUD, MD.
}

The Department of Radio-Diagnosis and Medical Imaging, Faculty of Medicine, Tanta University

\begin{abstract}
Background: Painful hip is a common problem in absence of a known acute trauma. MRI is a method of choice in detection of different causes of hip pain causing hip joint disability in adults including osseous, chondral and soft tissue abnormalities.

Aim of Study: This prospective study was conducted to evaluate the role of Magnetic Resonance Imaging (MRI) in diagnosis of different causes of hip joint disability in adults.

Patients and Methods: This study was conducted on 42 patients ( 22 females and 20 males) with age ranged from 18 68 years (mean of 41 years). All patients was subjected to plain X-ray and MRI of hip joint in different sequences, with additional post contrast (axial and coronal T1 WI) in 6 patents Patient history, clinical examination of the diseased hip, and laboratory investigations were performed.

Results: According to final results: 12 patients (28.6\% of 42 patients) presented clinically with hip pain but had negative plain X-ray and MRI findings, while other 30 patients of them (71.4\%) their MRI diagnoses were as follows: Avascular necrosis in $10(33.3 \%)$, transient osteoporosis in $4(13 \%)$, osteoarthritis in $3(10 \%)$, inflammatory arthritis in $2(6.7 \%)$, traumatic condition in $3(10 \%)$ and bone tumors in $8(27 \%)$.

Conclusion: MRI of the hip joint is an essential imaging modality in detection of different hip joint pathologies especially in patients presented clinically with hip pain but with negative conventional radiography.
\end{abstract}

Key Words: Hip joint - Disability - Magnetic resonance imaging.

\section{Introduction}

THE hip joint is a ball-and-socket joint. It is the articulation of the pelvis with the femur, which connects the axial skeleton with the lower extremity. The adult hip bone is formed by the fusion of the

Correspondence to: Dr. Mohammed A. Hammad,

The Department of Radio-Diagnosis and Medical Imaging, Faculty of Medicine, Tanta University ilium, the ischium, and the pubis. The 2 hip bones form the bony pelvis, along with the sacrum and the coccyx, and are united anteriorly by the symphysis pubis [1].

The hip joint is a major weight-bearing joint with significant mobility, with its attachment site for strong tendons. Hip disorders do not account for a large portion of exercise-related injuries, but they can pose a clinical dilemma since symptoms tend to be non-specific. Conventional radiographs may demonstrate some causes of hip pain, such as stress fractures and degenerative joint disease [2]

There are various causes of hip pain in adult causing hip joint disability such as musculoskeletal causes including: Avascular necrosis, osteoarthritis, inflammatory arthritis, Idiopathic Transient Osteoporosis of the Hip (ITOH), fractures around hip joint which may be traumatic, pathological or stress, bone and synovial tumors, bursitis, muscle and labral tears, tendonitis and metabolic conditions or non-musculoskeletal causes of hip pain in adults include: Hernia, aneurysm or nerve entrapment [3]

MRI proved to be highly accurate imaging modality allows clear differentiation of the normal anatomic features of the hip. Also it allows clear differentiation of the individual component of the normal joint from one another. In addition, MRI allows identification of the bone marrow, cortex, muscles, fascia, nerves and vessels with high contrast between these structures [4]

MRI is the diagnostic modality of choice for most disorders of the hip where radiographic findings are inconclusive. With MRI one can stage the pathology to prognosticate and influence therapeutic decisions [5]. 
Aim of the work:

Aim of this study is to evaluate the role of Magnetic Resonance Imaging (MRI) in diagnosis of different causes of hip joint disability in adults.

\section{Patients and Methods}

This retrospective study was conducted on a 42 adult patients complaining from hip joint disability including hip pain. The age of the selected patients ranged from 18 to 68 years with a mean of 41 years. They were referred from orthopedic and Physiotherapy Departments to MRI Unit in Radio-dIagnosis Department, Tanta University Hospitals over a period of 12 months starting from January 2018 till December 2018. Ethics Committee approval and informed consent were obtained.

\section{Inclusion criteria:}

- Adult patients (age >_18 years).

- Both sexes were included.

\section{Exclusion criteria:}

- Pediatric patients (age <18 years).

- Patients with a contraindication to MRI as having metal implants as pacemaker, aneurysm clips, joint replacement or any other electronic or magnetically activated implant as well as claustrophobic subjects.

\section{All patients were subjected to the following:}

1- History and clinical examination.

2- Laboratory investigation: Recent renal function test (urea and creatinine), Erythrocyte Sedimentation Rate (ESR), C-Reactive Protein (CRP) and Rheumatoid Factor (RF).

3- Imaging of the hip joint:

- Plain X-ray of hip joint: Antero-posterior view and lateral view according to each case requirement. joint:

- Magnetic Resonance Imaging (MRI) of hip

Patient preparation: The patient was asked about any contraindications as cardiac pacemakers, artificial valves or aneurysmal clips. They were instructed to remove all metallic objects such as hair pins, coins or ear rings, etc.... Then the procedure was explained for reassurance and the patients were informed about the length of the examination and the value of remaining motionless.

\section{Position of the patient:}

All the patients were examined in a supine position in comfortable and immobilized position, the legs straight and parallel to each other with $15^{\circ}$ internal rotation (feet first). The patient lies over spine coil and place the body coil over the pelvis.

MRI protocol: The following MRI sequences were done:

- Coronal T1 and STIR T2 WI, Axial T1 and STIR T2 WI, Sagittal T2 WI of the affected side.

- Post contrast axial and coronal T1 WI in 6 patients after using IV injection of $0.1 \mathrm{mmol} / \mathrm{kg}$ of gadolinium-DTPA (Magnivest) or gadolinium-DOTA (Dotarem).

- The sequences were performed using field of view (FOV): 38 X $38 \mathrm{~cm}$ for axial images, $42 \mathrm{X}$ $42 \mathrm{~cm}$ for coronal images and $35 \times 35 \mathrm{~cm}$ for sagittal images. It included the whole hip region. Matrix used was 256 X 196, slice thickness used was $5 \mathrm{~mm}$ and inter-slice gap employed was 0.5 $1 \mathrm{~mm}$.

- Computed Tomography (CT) of hip joint: Done in 4 patients after using IV injection of iopromide (Ultravist) or iohexol (Omnipaque) with a dose $1-2 \mathrm{ml} / \mathrm{kg}$ was carried out for comparison with MRI.

- Bone scan: Done in 3 patients after using IV injection of Tc99m-MDP in a dose $15-20 \mathrm{mCi}$. It used to confirm and differentiate between avascular necrosis and transient osteoporosis of femoral head.

4- Histopathological examination: Done in 8 patients to confirm the diagnosis by open biopsy in 6 patients and needle biopsy in 2 patients.

\section{Statistical methodology:}

The collected data were organized, tabulated and statistically analyzed using SPSS Version 25 (Statistical Package for Social Studies) created by IBM, Illinois, Chicago, USA. The following statistical methods were used for analysis of results.

- Descriptive statistics: Data were expressed as number and percentage.

- For numerical values, the range, mean and Standard Deviations (SD) were calculated.

For categorical variable, the number and percentage were calculated and differences between subcategories were tested by Fisher Exact Test (FET) due to small sample size of studied categories which did not guarantee normal distribution.

\section{Results}

All 42 patients presented with hip pain causing hip joint disability, whether spontaneous (non- 
traumatic causes) as found in $76.2 \%$ of the patients or with past history of trauma as found in $23.8 \%$ of the patients.

According to clinical presentation, all the studied patients were represented clinically by hip pain, 28 patients $(66.6 \%)$ of them were associated with other clinical symptoms as limping in 12 patients $(28.6 \%)$, while limitation of movement were found in 11 patients $(27 \%)$ and hip region swelling found in 5 patients $(12 \%)$ as described in (Table 1$)$.

Table (1): Clinical presentation of the studied 42 patients.

\begin{tabular}{lcc}
\hline Symptom & No. of patients & Percentage (\%) \\
\hline Hip pain & 42 & $100 \%$ \\
Limping & 12 & $28.6 \%$ \\
Swelling & 5 & $12 \%$ \\
Limitation of movement & 11 & $27 \%$
\end{tabular}

N.B: More than one symptom was revealed in the same patient.

Our study included 42 patients, 12 patients of them $(28.6 \%)$ presented clinically by pain in hip region but had negative conventional radiography and MRI findings, while the remaining 30 patients of them $(71.4 \%)$ had pathologic findings either in MRI or both MRI and conventional radiography. According to clinical presentation of the 12 patients, 7 patients $(58.3 \%$ of the 12 patients) diagnosed clinically as nerve entrapment (sciatica), 3 patients ( $25 \%$ of the 12 patients) diagnosed clinically as inguinal hernia and 2 patients $(16.7 \%$ of the 12 patients) diagnosed clinically as femoral hernia as described in (Table 2).

Table (2): Different causes of pain in the hip region in the studied 12 patients.

\begin{tabular}{lcc}
\hline Pathology & No. of patients & Percentage (\%) \\
\hline Sciatica & 7 & $58.3 \%$ \\
Inguinal hernia & 3 & $25 \%$ \\
Femoral hernia & 2 & $16.7 \%$ \\
\hline Total & 12 & $100 \%$ \\
\hline
\end{tabular}

As regard to the pathology of hip joints reported in 30 patients of the total studied symptomatic patients and after reviewing all radiological and MRI examinations, 10 patients were diagnosed as avascular necrosis of hip joint (33.3\%), 8 patients were diagnosed as bone tumors either primary or metastatic tumors $(27 \%)$, transient osteoporosis was diagnosed in 4 patients (13\%), osteoarthritis was diagnosed in 3 patients $(10 \%)$, also trauma was detected in 3 patients $(10 \%)$, and only 2 patients were diagnosed as inflammation $(6.7 \%)$. The different hip joint pathologies are demonstrated in (Table 3) \& Fig. (1).
Table (3): Number and percentage of different hip joint pathology in 30 studied symptomatic patients.

\begin{tabular}{lcc}
\hline Pathology & No. of patients & Percentage (\%) \\
\hline Avascular necrosis & 10 & $33.3 \%$ \\
Osteoarthritis & 3 & $10 \%$ \\
Transient osteoporosis & 4 & $13 \%$ \\
Inflammatory cases: & & \\
$\quad$ Septic arthritis & 1 & $6.7 \%$ \\
$\quad$ Rheumatoid arthritis & 1 & \\
Traumatic cases & 3 & $27 \%$ \\
Neoplastic cases: & 8 & \\
$\quad$ Osteoid osteoma & 2 & \\
$\quad$ Osteosarcoma & 2 & \\
$\quad$ Ewing sarcoma & 1 & \\
$\quad$ Osteochondroma & 1 & \\
$\quad$ Metastatic deposits & 2 & \\
\hline
\end{tabular}

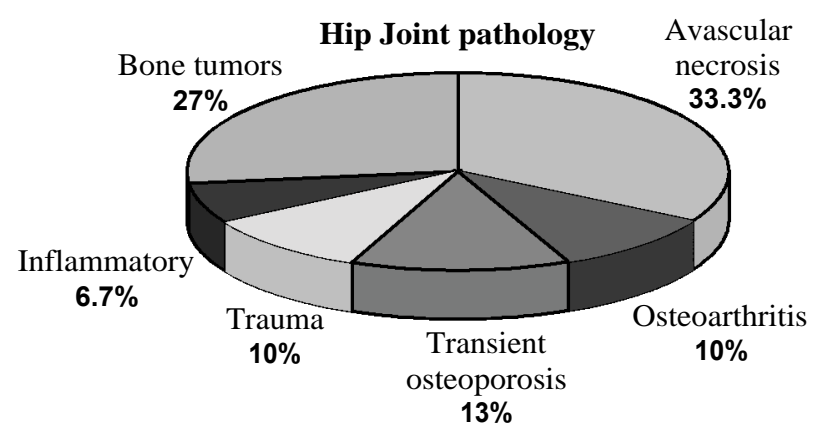

Fig. (1): The different hip joint pathologies (total no. $=30$ patients).

The results were analyzed regarding to the final outcome of the reviewed 30 positive studies depending on the criteria accepted as standard reference including management, histopathological results, and clinical or radiological imaging followup.

In patients with avascular necrosis (total 10 cases), 2 patients were diagnosed as bilateral grade I avascular necrosis where conventional radiography was normal and MRI had positive findings, other 4 patients were diagnosed as grade II avascular necrosis where conventional radiography and MRI findings had positive findings. Also, 2 patients were diagnosed as bilateral grade III avascular necrosis and 2 patients were diagnosed as grade IV avascular necrosis where conventional radiography and MRI findings had positive findings as shown in (Table 4).

Table (4): Number and percentage of avascular necrosis grading.

\begin{tabular}{lcc}
\hline Grades of avascular necrosis & No. of patients & Percentage (\%) \\
\hline Grade I & 2 & $20 \%$ \\
Grade II & 4 & $40 \%$ \\
Grade III & 2 & $20 \%$ \\
Grade IV & 2 & $20 \%$ \\
\hline
\end{tabular}


One of those patients was mis-diagnosed as grade I avascular necrosis, while after conservative treatment and follow-up, complete resolution of clinical and imaging findings at the affected side was noted with affection of the other side indicating transient osteoporosis.

So, regarding to this final outcome, MRI revealed 9 true positive cases (90\%), 1 false positive case $(10 \%)$ and no false negative cases or true negative cases and with sensitivity of $100 \%$, Positive Predictive Value (PPV) of $90 \%$ and accuracy of $90 \%$, while conventional radiography revealed 8 true positive cases (80\%), 2 false negative cases $(20 \%)$, and no true negative or false positive cases with sensitivity of $80 \%$, Positive Predictive Value (PPV) of $100 \%$ and accuracy of $80 \%$.

Three patients were diagnosed as osteoarthritis (10\% of the total 30 studied cases), conventional radiography and MRI had positive findings. So, regarding to the final outcome of the reviewed studies of those 3 osteoarthritis cases depending on the standard reference, MRI and conventional radiography were diagnostic with sensitivity, Positive Predictive Value (PPV) and accuracy 100\% for both.

In inflammatory cases (total 2 cases), one of them was septic arthritis where conventional radiography had negative findings and MRI had positive findings, and the other was rheumatoid arthritis where conventional radiography and MRI had positive findings. Clinical and laboratory correlation and follow-up were done to confirm diagnosis.

Regarding to the final outcome of the reviewed studies of those 2 inflammatory hip joint cases depending on the laboratory and clinical correlation accepted as standard reference, MRI was diagnostic with sensitivity, Positive Predictive Value (PPV) and accuracy $100 \%$, while conventional radiography revealed 1 true positive cases (50\%), 1 false negative cases (50\%), and no true negative or false positive cases with sensitivity of $50 \%$, Positive Predictive Value (PPV) of $100 \%$, and accuracy of $50 \%$.

In traumatic cases (total 3 cases), two of them (fracture neck femur and avulsion fracture of grater trochanter) where conventional radiography and MRI had positive findings, the third case (stress fracture) where conventional radiography was essentially normal and MRI had positive findings, two of them were subjected to clinical examination and follow-up and the third one underwent operation.
Regarding to the final outcome of the reviewed studies of those 3 traumatic hip joint cases depending on the clinical examination and follow-up accepted as standard reference, MRI was diagnostic with sensitivity, Positive Predictive Value (PPV) and accuracy $100 \%$, while conventional radiography revealed 2 true positive cases $(66.6 \%), 1$ false negative cases $(33.3 \%)$, and no true negative or false positive cases with sensitivity of $66.6 \%$, Positive Predictive Value (PPV) of $100 \%$ accuracy of $66.6 \%$.

In transient osteoporosis cases (total 4 cases), conventional radiography revealed suspicious positive findings in only 1 case, while MRI had positive findings in all cases, one of them was associated with osteoarthritis.

One of these cases showed no resolution or improvement of clinical symptoms after conservative treatment and follows-up after 6-8 months, revealed small hypodense nidus surrounded by bony sclerosis on follow-up CT scan which was proved to be osteoid osteoma after surgical excision and open biopsy.

So, regarding to this final outcome, MRI revealed 3 true positive cases (75\%), 1 false positive case $(10 \%)$ and no false negative cases or true negative cases and with sensitivity of $100 \%$, Positive Predictive Value (PPV) of $75 \%$ and accuracy of $75 \%$, while conventional radiography revealed 1 true positive cases (25\%), 3 false negative cases (75\%), and no true negative or false positive cases with sensitivity of $25 \%$, Positive Predictive Value (PPV) of $100 \%$ and accuracy of $25 \%$.

As regard to the 8 patients with hip joint neoplasm, conventional radiography and MRI were positive in all the cases. All of the tumors had been proved by biopsy either open or needle biopsy. Two cases were diagnosed by MRI as osteosarcoma, while after histo-pathological correlation; one of them was proved to be Ewing sarcoma.

So, regarding to this final outcome, both MRI and conventional radiography revealed 7 true positive cases $(87.5 \%), 1$ false positive case (10\%) and no false negative cases or true negative cases and with sensitivity of $100 \%$, Positive Predictive Value (PPV) of $87.5 \%$ and accuracy of $87.5 \%$.

The diagnostic accuracy of conventional radiography in the studied 30 patients with hip joint pathology is shown in (Table 5).

The diagnostic accuracy of MRI in the studied 30 patients as regard final outcome based on stand- 
ard method of each group with hip joint pathology is shown in (Table 6).

Clinical follow-up of the studied 12 patients with negative conventional radiography and MRI findings was done after further evaluation and medical or physical treatment that revealed resolution or improvement of symptoms and excluded hip joint pathology. Therefore, conventional radiography at this study defined 22 true positive cases ( $52.4 \%$ of the total studied 42 patients), 12 true negative cases (28.6\% of them), 7 false negative cases $(16.6 \%)$ and 1 false positive case $(2.4 \%$ of them), while MRI at this study defined 27 true positive cases $(64.3 \%$ of the total studied 42 patients), 12 true negative cases (28.6\% of them), 3 false positive cases $(7.1 \%)$ and no false negative cases.

The diagnostic accuracy of conventional radiography and MRI for the study-based statistical analysis in the total studied 42 patients is shown in (Table 7).

Table (5): Diagnostic accuracy of conventional radiography in the 30 patients with hip joint pathology.

\begin{tabular}{|c|c|c|c|c|c|c|c|}
\hline \multirow{2}{*}{ Pathology } & \multirow{2}{*}{$\begin{array}{l}\text { Conventional } \\
\text { radiography } \\
\text { results }\end{array}$} & \multicolumn{3}{|c|}{$\begin{array}{c}\text { Final } \\
\text { outcome }\end{array}$} & \multicolumn{3}{|c|}{$\begin{array}{c}\text { Diagnostic accuracy } \\
\text { of conventional radiography }\end{array}$} \\
\hline & & $+\mathrm{ve}$ & $-\mathrm{ve}$ & Total & Sens* & PPV* & Acc* \\
\hline \multirow{3}{*}{$\begin{array}{l}\text { - Avascular } \\
\text { necrosis }\end{array}$} & $+\mathrm{ve}$ & 8 & 0 & 8 & \multirow{3}{*}{$80 \%$} & \multirow{3}{*}{$100 \%$} & \multirow{3}{*}{$80 \%$} \\
\hline & - ve & 2 & 0 & 2 & & & \\
\hline & Total & 10 & 0 & 10 & & & \\
\hline \multirow[t]{3}{*}{ - Osteoarthritis } & +ve & 3 & 0 & 3 & \multirow{3}{*}{$100 \%$} & \multirow{3}{*}{$100 \%$} & \multirow{3}{*}{$100 \%$} \\
\hline & - ve & 0 & 0 & 0 & & & \\
\hline & Total & 3 & 0 & 3 & & & \\
\hline \multirow{3}{*}{$\begin{array}{l}\text { - Inflammatory } \\
\text { cases }\end{array}$} & +ve & 1 & 0 & 1 & \multirow{3}{*}{$50 \%$} & \multirow{3}{*}{$100 \%$} & \multirow{3}{*}{$50 \%$} \\
\hline & - ve & 1 & 0 & 1 & & & \\
\hline & Total & 2 & 0 & 2 & & & \\
\hline \multirow[t]{3}{*}{ - Trauma } & $+\mathrm{ve}$ & 2 & 0 & 2 & \multirow{3}{*}{$66.6 \%$} & \multirow{3}{*}{$100 \%$} & \multirow{3}{*}{$66.6 \%$} \\
\hline & - ve & 1 & 0 & 1 & & & \\
\hline & Total & 3 & 0 & 3 & & & \\
\hline \multirow{3}{*}{$\begin{array}{l}\text { - Transient } \\
\text { osteoporosis }\end{array}$} & $+\mathrm{ve}$ & 1 & 0 & 1 & \multirow{3}{*}{$25 \%$} & \multirow{3}{*}{$100 \%$} & \multirow{3}{*}{$25 \%$} \\
\hline & - ve & 3 & 0 & 3 & & & \\
\hline & Total & 4 & 0 & 4 & & & \\
\hline \multirow[t]{3}{*}{ - Bone tumors } & +ve & 7 & 1 & 8 & \multirow{3}{*}{$100 \%$} & \multirow{3}{*}{$87.5 \%$} & \multirow{3}{*}{$87.5 \%$} \\
\hline & - ve & 0 & 0 & 0 & & & \\
\hline & Total & 7 & 0 & 8 & & & \\
\hline
\end{tabular}

Table (6): Diagnostic accuracy of MRI in the studied 30 patients with hip joint pathology.

\begin{tabular}{|c|c|c|c|c|c|c|c|}
\hline \multirow{2}{*}{ Pathology } & \multirow{2}{*}{$\frac{\text { MRI }}{\text { results }}$} & \multicolumn{3}{|c|}{ Final outcome } & \multicolumn{3}{|c|}{ Diagnostic accuracy of MRI } \\
\hline & & $+\mathrm{ve}$ & - ve & Total & Sens* & $\mathrm{PPV}^{*}$ & Acc* \\
\hline \multirow{3}{*}{$\begin{array}{c}\text { Avascular } \\
\text { necrosis }\end{array}$} & +ve & 9 & 1 & 10 & \multirow{3}{*}{$100 \%$} & \multirow{3}{*}{$90 \%$} & \multirow{3}{*}{$90 \%$} \\
\hline & - ve & 0 & 0 & 0 & & & \\
\hline & Total & 9 & 1 & 10 & & & \\
\hline \multirow[t]{3}{*}{ - Osteoarthritis } & + ve & 3 & 0 & 3 & \multirow{3}{*}{$100 \%$} & \multirow{3}{*}{$100 \%$} & \multirow{3}{*}{$100 \%$} \\
\hline & - ve & 0 & 0 & 0 & & & \\
\hline & Total & 3 & 0 & 3 & & & \\
\hline \multirow{3}{*}{$\begin{array}{l}\text { - Inflammatory } \\
\text { cases }\end{array}$} & + ve & 2 & 0 & 2 & \multirow{3}{*}{$100 \%$} & \multirow{3}{*}{$100 \%$} & \multirow{3}{*}{$100 \%$} \\
\hline & - ve & 0 & 0 & 0 & & & \\
\hline & Total & 2 & 0 & 2 & & & \\
\hline \multirow{3}{*}{ - Trauma } & + ve & 3 & 0 & 3 & \multirow{3}{*}{$100 \%$} & \multirow{3}{*}{$100 \%$} & \multirow{3}{*}{$100 \%$} \\
\hline & - ve & 0 & 0 & 0 & & & \\
\hline & Total & 3 & 0 & 3 & & & \\
\hline \multirow{3}{*}{$\begin{array}{l}\text { - Transient } \\
\text { osteoporosis }\end{array}$} & $+\mathrm{ve}$ & 3 & 1 & 4 & \multirow{3}{*}{$100 \%$} & \multirow{3}{*}{$75 \%$} & \multirow{3}{*}{$75 \%$} \\
\hline & - ve & 0 & 0 & 0 & & & \\
\hline & Total & 3 & 1 & 4 & & & \\
\hline \multirow[t]{3}{*}{ - Bone tumors } & + ve & 7 & 1 & 8 & \multirow{3}{*}{$100 \%$} & \multirow{3}{*}{$87.5 \%$} & \multirow{3}{*}{$87.5 \%$} \\
\hline & - ve & 0 & 0 & 0 & & & \\
\hline & Total & 7 & 1 & 8 & & & \\
\hline
\end{tabular}


Table (7): Overall diagnostic accuracy of conventional radiography versus MRI in the total studied 42 patients dependent on statistical analysis.

\begin{tabular}{lcc}
\hline Statistical analysis & Conventional radiography & MRI \\
\hline Sensitivity & $75.8 \%$ & $100 \%$ \\
Specificity & $92.3 \%$ & $80 \%$ \\
PPV & $95.6 \%$ & $90 \%$ \\
NPV & $63.2 \%$ & $100 \%$ \\
Accuracy & $81 \%$ & $92.8 \%$ \\
\hline
\end{tabular}

\section{Illustrated cases:}

\section{Case (1):}
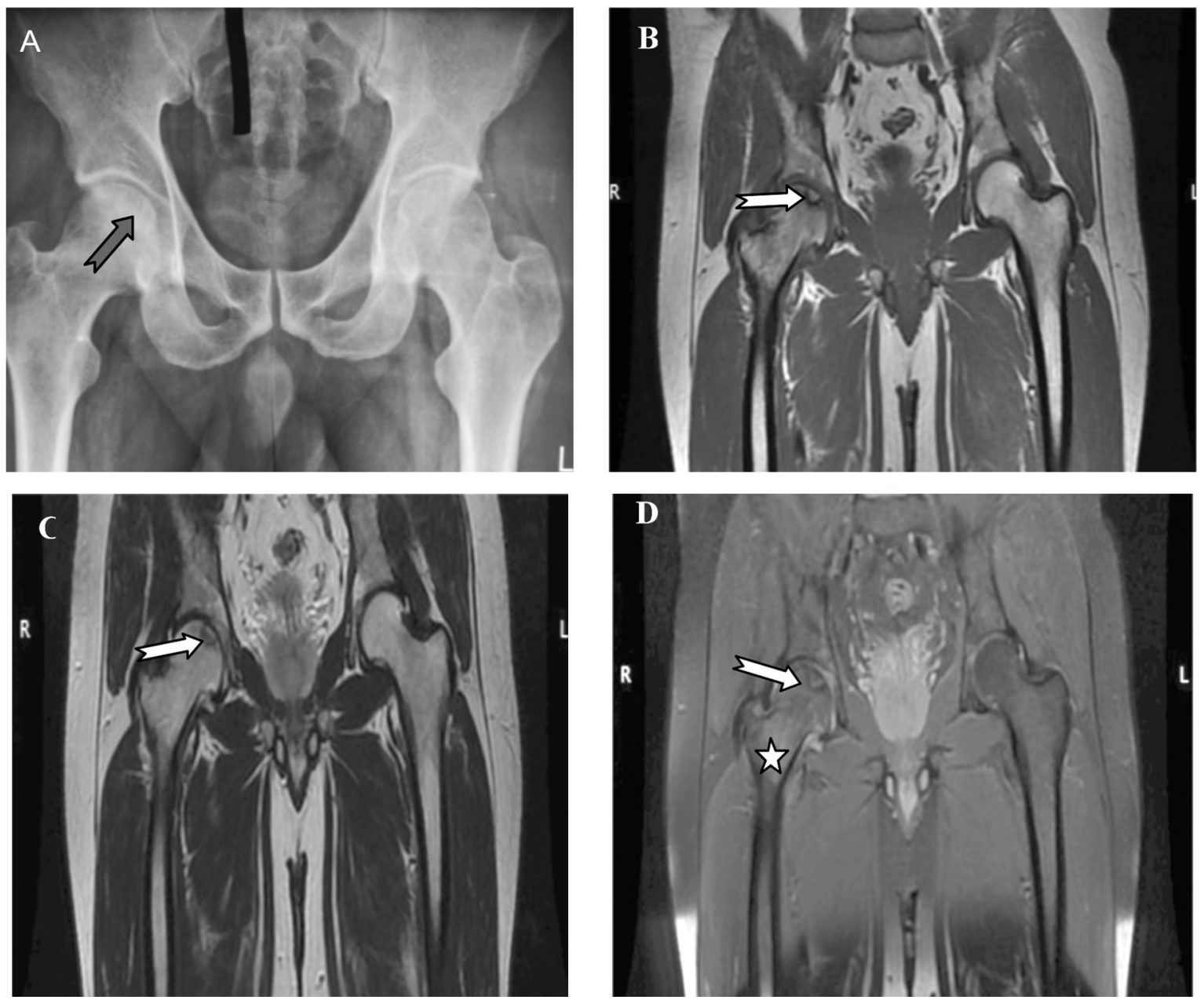

Fig. (2): (A-D): Male patient aged 45 years, presented by right side hip pain (A) Plain X-ray both hip joint (A.P.) revealed an area of sclerosis seen at supero-medial aspect of right femoral head (red arrow). (B, C \& D) MR T1 WI, T2 WI and STIR sequences (coronal section) respectively of both hip joints revealed low signal intensity line (white arrow) at the right femoral epiphysis separating necrotic from normal bone. Patchy area of abnormal high SI in T2 WI \& STIR images seen at the right femoral neck (edema) (star).

Final diagnosis: Right femoral head avascular necrosis Grade II. 
Case (2):
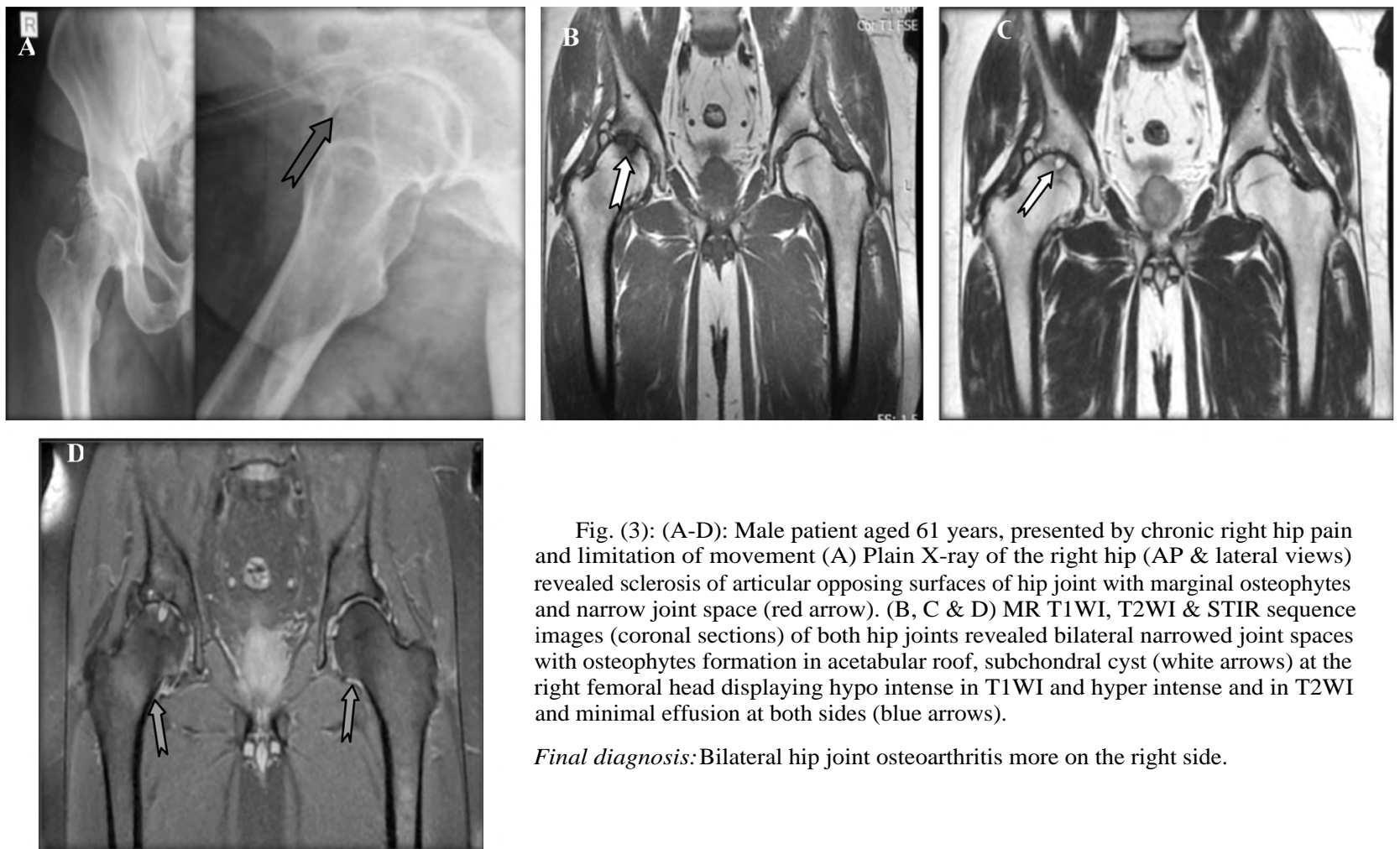

Fig. (3): (A-D): Male patient aged 61 years, presented by chronic right hip pain and limitation of movement (A) Plain X-ray of the right hip (AP \& lateral views) revealed sclerosis of articular opposing surfaces of hip joint with marginal osteophytes and narrow joint space (red arrow). (B, C \& D) MR T1WI, T2WI \& STIR sequence images (coronal sections) of both hip joints revealed bilateral narrowed joint spaces with osteophytes formation in acetabular roof, subchondral cyst (white arrows) at the right femoral head displaying hypo intense in T1WI and hyper intense and in T2WI and minimal effusion at both sides (blue arrows).

Final diagnosis:Bilateral hip joint osteoarthritis more on the right side.

Case (3):
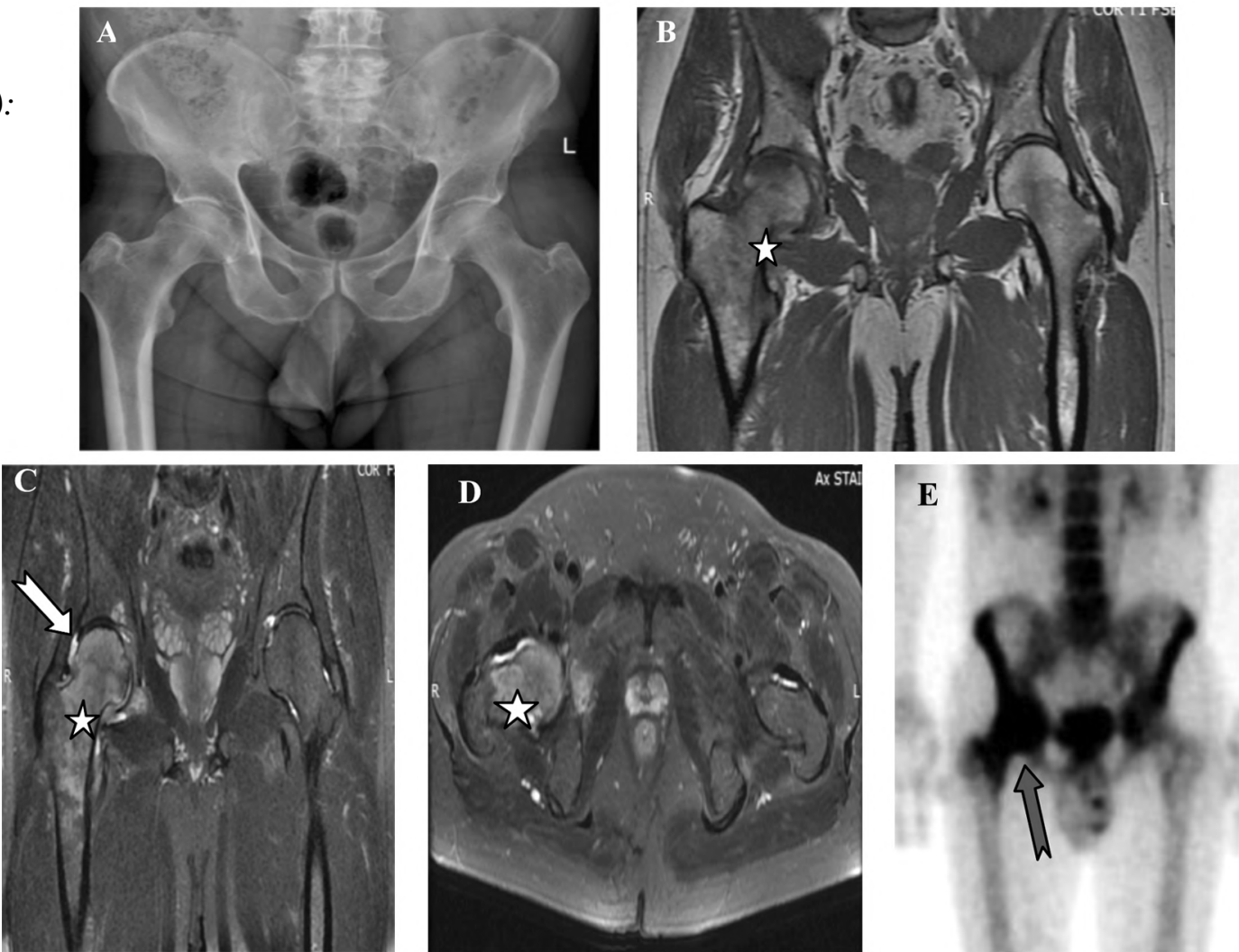

Fig. (4): (A-E): Male patient aged 36 years, presented by right hip pain (A) Plain X-ray of the both hip joints (AP) revealed no abnormal findings. (B) MRI coronal T1WI, (C) MRI coronal T2WI \& (D) MRI axial STIR sequence images of both hip joints revealed a large area of abnormal SI (low SI in T1WI and high SI in T2WI \& STIR) seen involving whole right femoral head and neck creeping inferiorly to the intertrochanteric region as well as right accetabulum (stars), with preserved femoral head and no evidence of cortical irregularity or structural collapse (white arrow) (E) Bone scan (anterior view) revealed: Markedly increased homogeneous uptake in the femoral head of right hip joint (red arrow).

Final diagnosis: Right femoral head and neck marrow edema pattern (Transient migratory osteoporosis (TOP). 
Case (4):
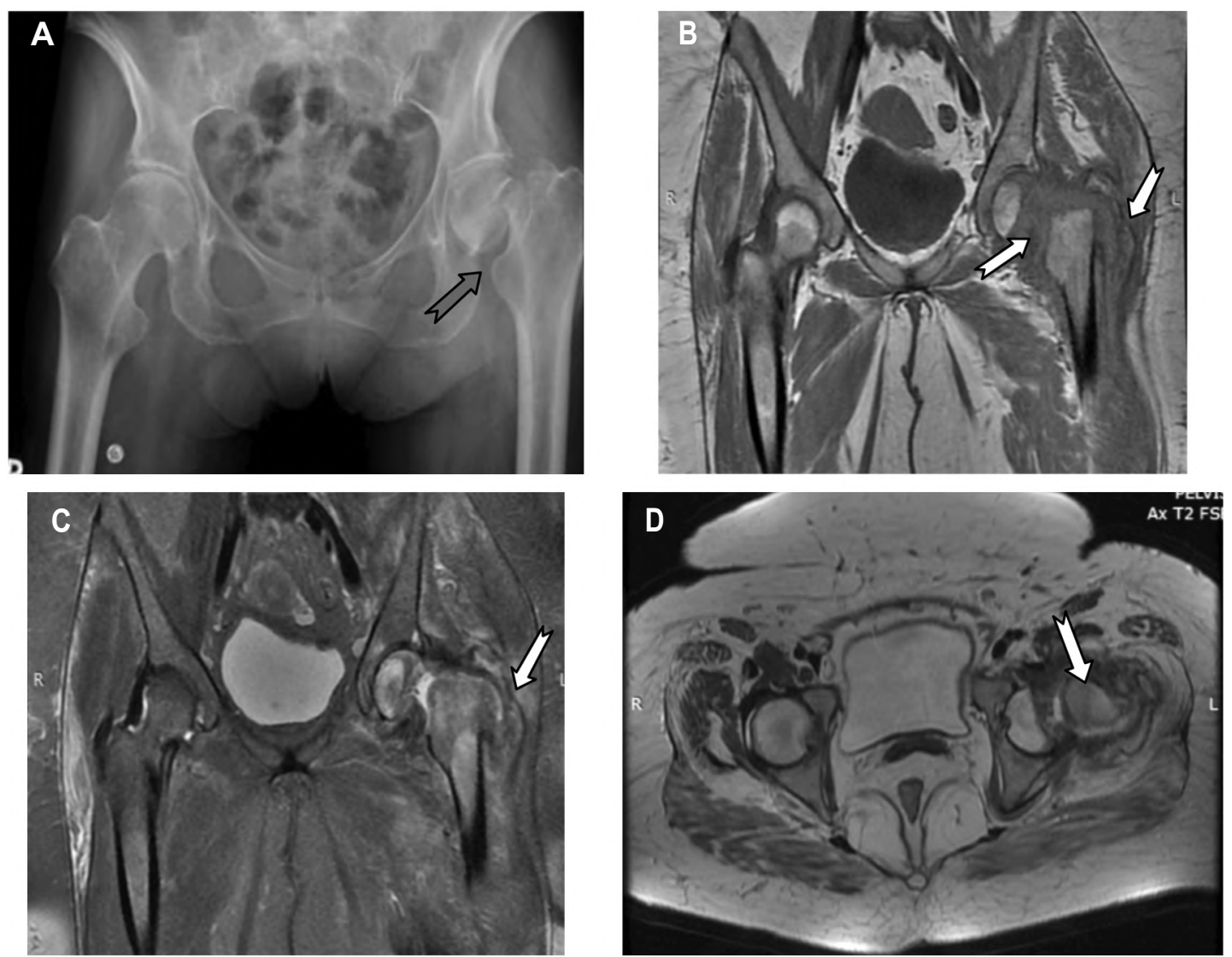

Fig. (5): (A-D): Female patient aged 52 years, presented by severe left hip pain associated with swelling and limitation of movement (A) Plain X-ray of the both hip joints (AP) revealed complete fracture line seen at left femoral neck with displacement of the femoral shaft laterally (red arrow) (B) Мю coronal T1WI, (C) Мю coronal STIR \& (D) Мю axial T2WI images of both hip joints revealed complete displaced fracture of the left femoral neck with displacement of the femoral shaft laterally (white arrows), associated with an ill defined soft tissue mass lesion seen within the surrounding muscles, displaying isointense signal in T1WI and high signal in T2WI \& STIR sequences denoting old intra-muscular hematoma (yellow arrow).

Final diagnosis:Fracture of left femoral neck associated with intra-muscular hematoma.

\section{Case (5):}
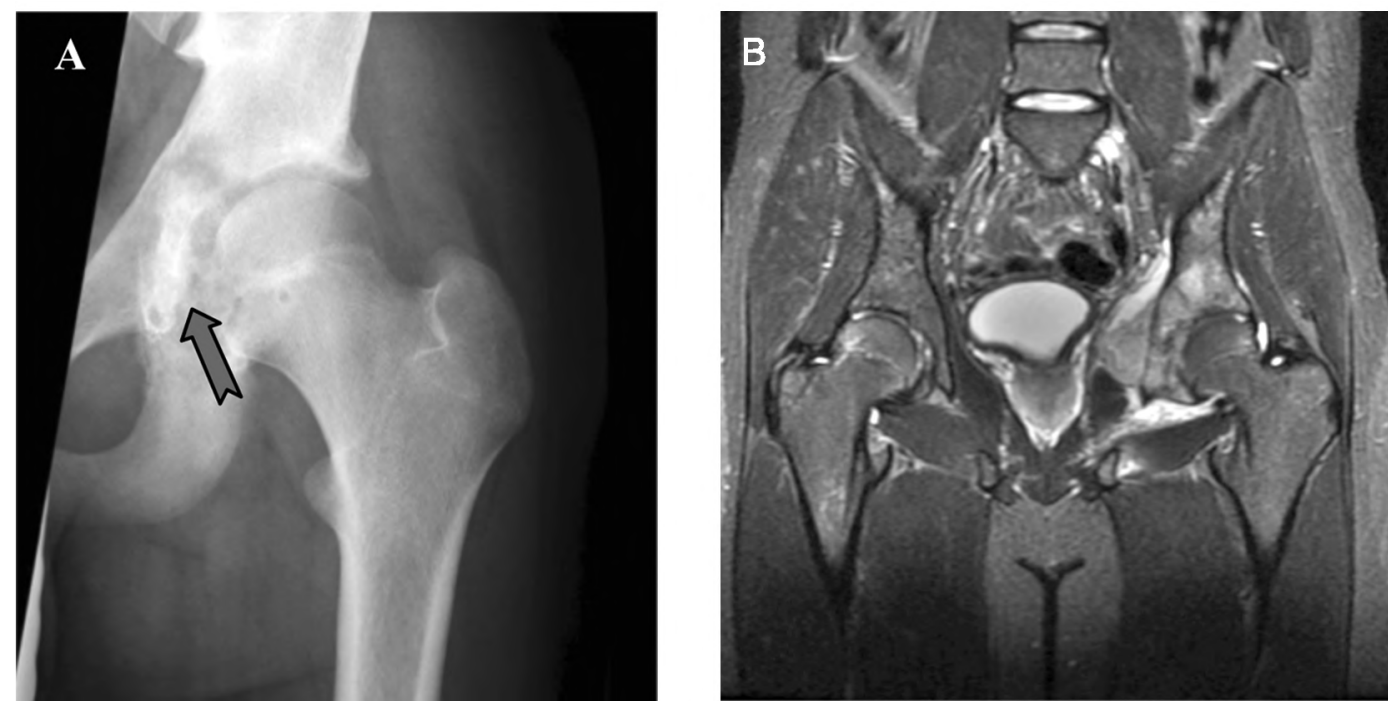

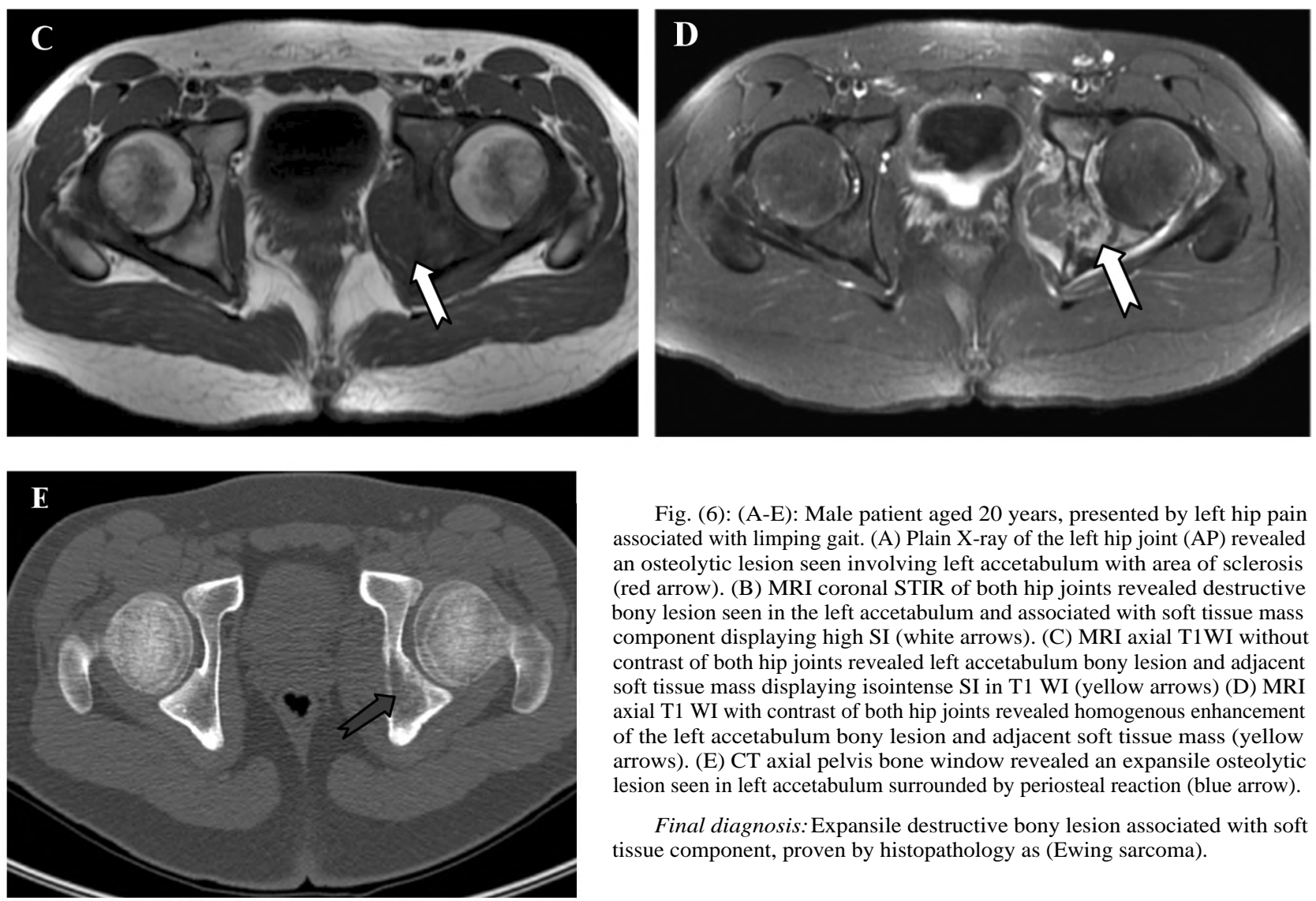

Fig. (6): (A-E): Male patient aged 20 years, presented by left hip pain associated with limping gait. (A) Plain X-ray of the left hip joint (AP) revealed an osteolytic lesion seen involving left accetabulum with area of sclerosis (red arrow). (B) MRI coronal STIR of both hip joints revealed destructive bony lesion seen in the left accetabulum and associated with soft tissue mass component displaying high SI (white arrows). (C) MRI axial T1WI without contrast of both hip joints revealed left accetabulum bony lesion and adjacent soft tissue mass displaying isointense SI in T1 WI (yellow arrows) (D) MRI axial T1 WI with contrast of both hip joints revealed homogenous enhancement of the left accetabulum bony lesion and adjacent soft tissue mass (yellow arrows). (E) CT axial pelvis bone window revealed an expansile osteolytic lesion seen in left accetabulum surrounded by periosteal reaction (blue arrow).

Final diagnosis: Expansile destructive bony lesion associated with soft tissue component, proven by histopathology as (Ewing sarcoma).

\section{Discussion}

The hip joint is a primary weight-bearing joint. Disorders of the hip are potential source of debility to patients of all ages. In absence of known acute trauma, hip pain is a common diagnostic problem with many etiologies [6].

In this study, all patients underwent conventional radiography at first. This agrees with Lang et al., 2010 [7] who reported that any evaluation of hip disease through imaging should begin with the conventional radiography which is the cheapest way to assess the problem.

According to clinical presentation, all the studied patients were represented clinically by hip pain, and other associated clinical symptoms as limping in 12 patients, swelling in 5 patients and limitation of movement in 11 patients. This agrees with Clohisy et al., 2009 [8] who performed their study on 52 patients presented clinically by hip pain and associated with limping in 35 patients representing $67 \%$ and limitation of movement in 30 patients representing $57 \%$.

This study included 42 patients, thirty patients of them presented with hip joint pathology according to clinical and imaging findings. Reviewing of conventional radiography and MRI of hip joints in the 30 patients with hip joint pathology revealed different verities of hip pathologies including avascular necrosis, osteoarthritis, inflammation, trauma, transient osteoporosis and neoplasm. It was reported that the most common causes of hip pain in adults are avascular necrosis detected in 10 patients $(10 \%)$ and bone tumors (either primary or secondary tumor) in 8 patients ( $27 \%$ of the cases). This agrees with the fact that that hip pain may be caused by abnormality in the bone marrow, supporting soft tissue, muscles, synovium or cartilage causes of hip pain include avascular necrosis, transient osteoporosis, inflammation, osteoarthritis, traumatic and neoplastic cause as reported by Shindle et al., 2006 [9]. Kaushik et al., 2012 [10] stated that the avascular necrosis is the most common pathology affecting hip joint.

The current study is similar to many researches that studied the role of MRI in detecting the cause of chronic hip pain. This agrees with El-Zawawi et al., 2018 [11] that conducted their study on 35 patients with chronic hip pain; the final MRI diagnoses in these patients were as follows: Avascular necrosis in $10(28.57 \%)$, transient synovitis in eight $(22.86 \%)$, septic arthritis in four (11.43\%), malignant neoplasm in four (11.43\%), osteoarthritis in 
two $(5.71 \%)$, bone marrow contusion in three $(8.57 \%)$, migratory osteoporosis in one $(2.86 \%)$, bursitis in one $(2.86 \%)$, and stress fractures in two $(5.71 \%)$ patients.

Regarding avascular necrosis, the current study reported that avascular necrosis was found in 10 cases (33.33\% of all cases) with Grade II avascular necrosis being the most common grade found in 4 cases (40\%), while Grade I, III \& IV were found in $20 \%$ of cases for each one, also bilateral joint affection (noted in 5 cases) with avascular necrosis is more than unilateral affection. This agrees with Fukushima, et al., 2010 [12] who reported that distribution of the avascular necrosis grading showed that the most frequent is Grade II (28\%) followed by Grade III (25\%) and Grade IV (19\%).

In our study, one of patients with avascular necrosis was mis-diagnosed as Grade I avascular necrosis, while after conservative treatment and follow-up, complete resolution of clinical and imaging findings at the affected side was noted with affection of the other side indicating transient osteoporosis. This agrees with Trepman, and King, 1992 [13] who found that a case with bilateral idiopathic hip pain was diagnosed by MRI as being consistent with osteonecrosis. Despite evaluation by multiple physicians and imaging methods, the correct diagnosis of transient osteoporosis of the hip was delayed until after resolution of the syndrome.

Regarding osteoarthritis, the present study included 3 cases of osteoarthritis. Their conventional radiography revealed narrow joint space, osteophytes formation and fine articular irregularity. MR images showed evidence of osteoarthritic changes of both hip joints or on one side in the form of cartilage thinning, small erosions, narrow joint space and marginal sclerosis with developing osteophytes and subchondral cysts in severe cases. This agrees with Jessel et al., 2009 [14] who reported that the earliest sign in osteoarthritis is a decreased joint space, usually maximal in the superior weight bearing region but sometimes affecting the entire joint. Later signs are sub-articular sclerosis cyst formation and osteophytes formation.

Regarding inflammatory arthritis, this study included 2 cases of inflammatory arthritis. One of them had normal conventional radiography and the other case its conventional radiography showed irregular femoral and accetabular articular surface and bilateral cortical erosions. This agrees with McInnes, and Schett, 2011 [15] who stated that in inflammatory arthritis, most of cases showed subchondral edema and cyst formation. Joint effusion is readily visualized in many cases.

Regarding Transient osteoporosis, this study included 4 cases of transient osteoporosis with three of them has normal conventional radiography and one case has minimal Subchondral cortical irregularity. MR images showed patchy diffuse area of abnormal marrow signal intensity creeping to inter-trochanteric region in the form of low marrow signal intensity on T1 WI and high signal intensity on T2 WI and STIR images, that may be affect one side or both sides, or may be alternative to other side after complete resolution in the affected side by conservative treatment and followup. This agrees with the study done by Gemmel, et al., 2012 [133] on transient osteoporosis, that all patient presented clinically by idiopathic hip pain even bilateral or unilateral and the conventional radiography showed no obvious abnormality. MRI images showed an ill defined area of decreased signal intensity on T1 WI and increased signal intensity on T2 WI when compared with the intensity of normal bone marrow in the proximal femur and accetabulum. This pattern involves femoral head and extends for a variable distance into femoral neck and inter-trochanteric regions.

In our study, one of patients with transient osteoporosis showed no resolution or improvement of clinical symptoms after conservative treatment and follows-up after 6-8 months, revealed small hypodense nidus surrounded by bony sclerosis on follow-up CT scan which was proved to be osteoid osteoma after surgical excision and open biopsy. This agrees with Scalici, et al., 2011 [17] who reported that osteoid osteoma when arising in unusual intra-articular locations, diagnosis may appear confusing and lead to delayed management. This confirmed with a case with intra-articular osteoid osteoma of the hip involving the posteroinferior quarter of the femoral head. The initial MRI diagnosis was transient osteoporosis and could not identify the lesion whereas it was detected by thin slice CT imaging. Followed by complete surgical excision of the tumor, the diagnosis could be confirmed after histo-pathological analysis.

Regarding hip joint neoplasm, this study included 8 neoplastic cases. Two of them were secondary bone tumors as metastatic lesions and other sex cases of primary bone tumors (two patients with osteoid osteoma, two patients with osteosarcoma, one patient with Ewing sarcoma and one patient of osteochondroma). The interpretation of conventional radiography in MRI in this entity depended on specific criteria for each neoplasm as well as 
correlation with patient age, clinical presentation and history of other primary tumors. All of them were confirmed after histo-pathological correlation.

In our study, two cases were diagnosed by MRI as osteosarcoma, while after histo-pathological correlation; one of them was proved to be Ewing sarcoma.

Among the 8 cases with hip neoplasm, malignancy was found in 5 cases either in hip or femoral bones including 2 patients with bone metastases, 2 patients with osteosarcoma and 1 patient with Ewing's sarcoma and, and benign tumors were found in 3 cases in femoral neck including 2 cases of osteoid osteoma and 1 case of osteochondroma. These findings are in agreement with those of the study done by Bloem, and Reidsma, 2012 [18] on bone and soft tissue tumors of hip and pelvis, they found that the majority of tumors in the pelvis are malignant (metastases, myeloma, chondrosarcoma, Ewing sarcoma, osteosarcoma, and MFH/ fibrosarcoma), while those in the proximal femur are in majority benign (fibrous dysplasia, solitary bone cyst, and osteoid osteoma).

The initial evaluation of suspected hip masses begins with conventional radiography. Although it is frequently unrewarding, it can provide invaluable information when it is positive, it is useful in establishing a tissue-specific tumors; it can reveal calcifications in soft tissue tumors which can be suggestive or sometimes characteristic to a specific diagnosis. Also, it can provide an excellent method to assess osseous involvement in soft tissue tumors, such as remodeling, periosteal reaction, associated pathological fracture or overt destruction [19].

MR imaging has emerged as the preferred imaging modality of choice for evaluating osseous and soft tissue masses of the hip by providing information for diagnosis and staging. The MR imaging signal characteristics and enhancement patterns of malignant and benign hip tumors permit specific diagnoses in some cases [19].

\section{Conclusion:}

MRI has become an essential imaging modality in musculoskeletal system in general and in hip region specifically. It is a non-invasive technique with no radiation hazards, informative and essential in painful hip.

Conventional radiography has relatively high sensitivity and specificity in evaluation of some pathological entities of hip joint as fractures and osteoarthritis; however, it was insufficient for evaluating early stages of other diseases.

In this study we suggest to use MRI as a routine examination in all cases with painful hip joint especially whose diagnosed by clinical examination with pain in hip joint but had negative conventional radiography.

\section{References}

1- LEE S., NARDO L., KUMAR D., et al.: Scoring hip osteoarthritis with MRI (SHOMRI): A whole joint osteoarthritis evaluation system. Journal of Magnitic Resonance Imaging, 41: 1549-57, 2015.

2- FERGUSON S.J., BRYANT J.T., GANZ R., et al.: The influence of the acetabular labrum on hip joint cartilage consolidation: A poroelastic finite element model, Journal of Biomechanics, 33: 953-60, 2000.

3- LAFFORGUE P.: Pathophysiology and natural history of avascular necrosis of bone. Joint Bone Spine, 73: 500-7, 2006.

4- VERBEETEN K.M., HERMANN K.L., HASSELQVIST M., et al.: The advantages of MRI in the detection of occult hip fractures. European Radiology, 15: 165-9, 2005.

5- SUGANO N., ATSUMI T., OHZONO K., et al.: The 2001 revised criteria for diagnosis, classification, and staging of idiopathic osteonecrosis of the femoral head. Journal of Orthopaedic Science, 7: 601-5, 2002.

6- BOYKIN R.E., ANZ A.W., BUSHNELL B.D., et al.: Hip instability. The Journal of the American Academy of Orthopaedic Surgeons, 19: 340-9, 2011.

7- LANG P.H., STEINES D., LIEW S.W., et al.: Methods for the compensation of imaging technique in the processing of radiographic images. American Journal of Roentgenology, 1: 4-10, 2010.

8- CLOHISY J.C., KNAUS E.R., HUNT D.M., et al.: Clinical presentation of patients with symptomatic anterior hip impingement. Clinical orthopaedics and related research, 467: 638-44, 2009.

9- SHINDLE M.K., RANAWAT A.S. and KELLY B.T. Diagnosis and management of traumatic and atraumatic hip instability in the athletic patient. Clinics in Sports Medicine, 25: 309-26, 2006.

10- KAUSHIK A.P., DAS A. and CUI Q.: Osteonecrosis of the femoral head: An update in year 2012. World Journal of Orthopedics, 3: 49-57, 2012.

11- EL ZAWAWI M.S.E., HABIB R.M. and EL ZEFZAF D.A.: Role of magnetic resonance imaging in the assessment of chronic hip pain in adults. Menoufia Medical Journal, 2: 514-9, 2018.

12- FUKUSHIMA W., FUJIOKA M., KUBO T., et al.: Nationwide epidemiologic survey of idiopathic osteonecrosis of the femoral head. Clinical Orthopaedics and Related Research, 468: 2715-24, 2010.

13- TREPMAN E. and KING T.V.: Transient osteoporosis of the hip misdiagnosed as osteonecrosis on magnetic resonance imaging. Orthopaedic review, 21: 1089-91, 1992. 
14- JESSEL R.H., ZILKENS C., TIDERIUS C., et al.: Assessment of osteoarthritis in hips with femoroacetabular impingement using delayed gadolinium enhanced MRI of cartilage. Journal of Magnetic Resonance Imaging, 30: 1110-5, 2009

15- McINNES I.B. and SCHETT G.: The pathogenesis of rheumatoid arthritis. The New England Journal of Medicine, 365: 2205-19, 2011.

16- GEMMEL F., VAN DER VEEN H.C., VAN SCHELVEN W.D., et al.: Multi-modality imaging of transient osteoporosis of the hip. Acta Orthopaedica Belgica, 78: 61927, 2012.
17- SCALICI J., JACQUEL A., MUKISH P., et al.: Intraarticular osteoid osteoma of the hip misdiagnosed by MRI: An unusual cause of unexplained hip pain. Orthopaedics \& Traumatology Surgery \& Research, 97: 8815,2011 .

18- BLOEM J.L. and REIDSMA I.I.: Bone and soft tissue tumors of hip and pelvis. European Journal of Radiology, 12: 3793-801, 2012.

19- BANCROFT L.W., PETERSON J.J. and KRANSDORF M.J.: MR Imaging of Tumors and Tumor-Like Lesions of the Hip. Magnetic Resonance Imaging Clinics of North America, 4: 757-74, 2005.

\section{التصوير بالرنين المغناطيسى التموري فى تشخيص قصور مفصل الحوض فئى البيالغين}

تعد آلام الفخذ من الآمراض الشائعة وخصوصاً فى حالة عدم تواجد آى إصابات حادة، ويمكن آن يعزى هذا الآلم إلى العديد من الآسباب

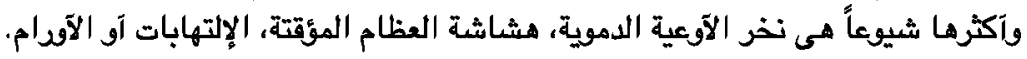

تهدف هذه الدراسة إلى توضيع دود التصوير بالرنين المغناطيسى فى تشخيص مسبيات آلام مفصل الفخذ لدى البالغين التى تتسبب فى في قصور مفصل الفخذ وتحديد دقة كل من التصوير بالآشعة العادية والرنين المفناطيسى في في آمراض مفصل الفئ الفخذ.

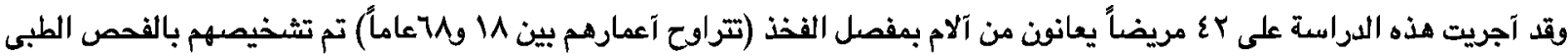
بآلام فى مفصل الفخذ بسبب بعض آمراض مفصل الفخذ وخضع جميع المرضى للتصوير بواسطة كل من الآشعة العادية والتصوير بالرنين

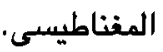

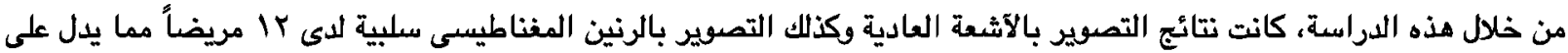

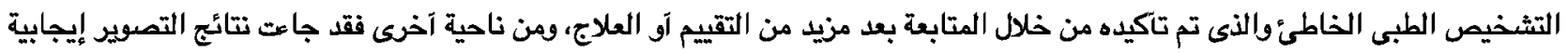

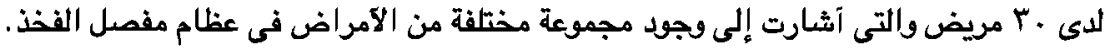

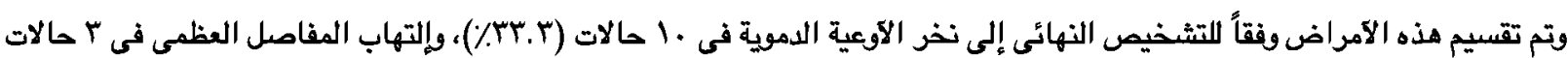

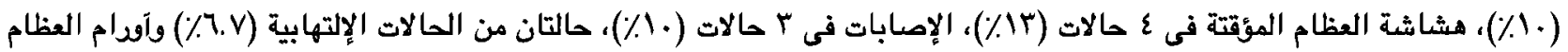

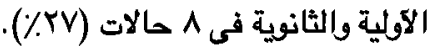

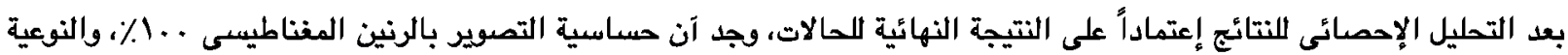

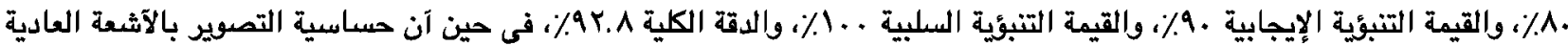

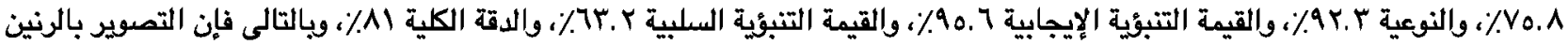

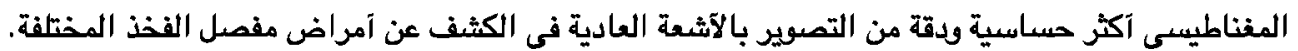

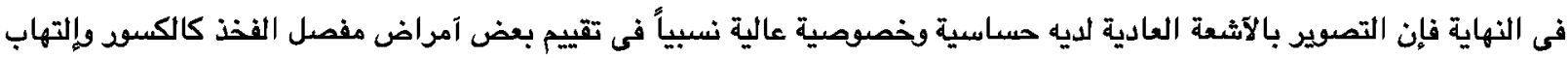

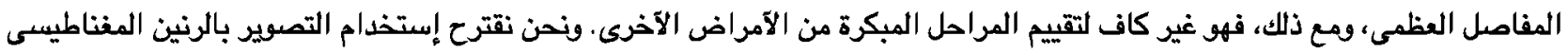

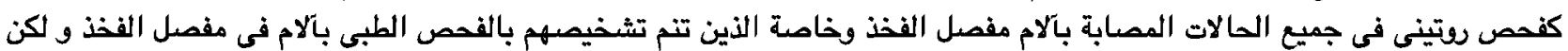
لديهم نتائج سلبية فى التصوير بالآشعة العادية.

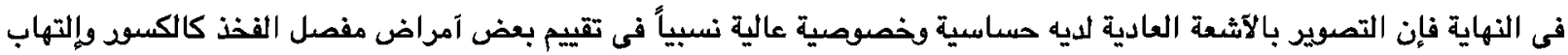

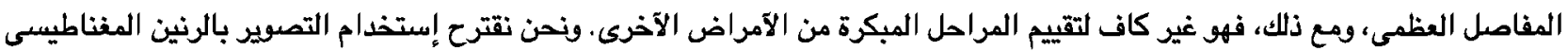

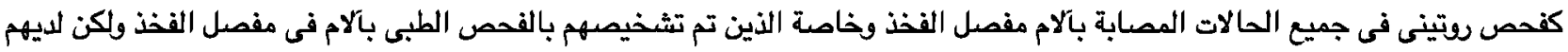

